\author{
여러 가지 조사료를 급여한 꽃사슴 (Servus nippon)의 채식습성에 \\ 관한 연구 \\ 이인덕 $\square$ 이형석*
}

\title{
Study on the Food Habits of Sika Deer (Servus Nippon) Fed with Various Roughage Sources
}

In Duk Lee and Hyung Suk Lee*

\begin{abstract}
The object of this experiment was to investigate the food habits of sika deer fed with various roughage sources. The feeding trials were conducted at Chungnam National University and Unbong Animal Genetic Resources Station in 2007. The experimental roughages sources were five including 25 species in all; grass sources; 5 species (Lolium perenne, Festuca arundinacea, Poa pratensis, Agrostis alba and mixed grass), legume sources; 5 species (Trifolium pratense, Medicago sativa, Trifolium repens, Melilotus officinalis and Vicia villosa), browse sources; 5 species (Quercus serrata Thunb., Prunus jamasakura Sieb., Quercus aliena Blume, Robinia pseudoaccacia and Pinus densiflora), weed sources; 5 species (Artemisia princeps Pampanini, Erigeron canadensis, Alopecurus aegualis Sobolewski, Echinochloa crusgalli var. frumentacea (Roxb.) Wight and Rumex crispus), and native grass sources; 5 species (Zoysia japonica Steudel, Agropyron tsukushiense var. transiens (Hack) Ohwi., Arundinella hirta (Thunb.) Tanaka, Miscanthus sinensis Anderss and Phragmites comunis Trin). Five sika deer were selected which had nearly the same body weight (average $92.5 \mathrm{~kg}$ ) as experimental animal. Experimental roughages were prepared by $0.5 \mathrm{~kg}$ (DM basis) per 1 species fed to sika deer, and the experiment was carried out from 08:00 to the next day 06:00. The chemical composition and dry matter digestibility of each roughage source and species were significantly different at the sampling area, plant species, growth stages and cutting period. The sika deer ate more roughages which had low fibrous contents, but high dry matter digestibility. Among all the 25 species of roughages, the favorite intake species ranking by sika deer was observed like this: Quercus aliena Blume, Prunus jamasakura Sieb, Quercus serrata Thunb. and Trifolium pratense, respectively, and the lower intake species was Phragmites comunis Trin. On the other hand, compared to each roughage source, total intake amount by sika deer was showed as browse (36.5\%), Legumes (34.2\%), grasses (14.0\%), native grasses (13.5\%) and weeds (1.8\%), respectively. Based on the result, the food habits of sika deer seems to be closer to typically browser type.
\end{abstract}

(Key words : Food habits, Sika deer, Relative intake percentage, Intake ranking, Browser type)

충남대학교 농업생명과학대학 (Division of Animal Science and Resources, College of Agriculture and Life Science, Chungnam National University, Daejon 305-764, Korea)

* 우송정보대학 (Woosong Information College, Daejon, 300-715, Korea)

Corresponding author: Hyung Suk Lee, Woosong Information College, Daejon 300-715, Korea

Tel: +82-42-629-6175 Fax: +82-42-629-6177 E-mail: hs1207@hanmail.net 


\section{I. 서 론}

사슴은 1921년 함경북도지방에서 러시아인에 의해 처음 사육된 이래 지금까지 국내에서는 꽃사슴 (sika deer), 래드디어 (red deer) 및 앨크 (elk)가 주로 사육되고 있다. 사슴을 사육하는 목적은 사슴고기보다는 녹용생산이 주목적이라 하겠다(이 등, 1990). 사슴은 방목이나 조사료 위주로 사육이 가능하고, 분뇨에 의한 환경오 염이 비교적 적고, 사육방법도 어렵지 않아 한 때는 고소득업이나 사치 업종으로 오인받기도 하였다.

그러나 최근에는 외국에서 값싼 녹용이 수입 되고 녹용의 소비가 감소되면서 양록업은 상당 한 어려움에 처해 있어 사료비의 절감을 통한 사육비를 낮출 수 있는 방안이 시급하다고 하 겠다. 다행스럽게도 사슴은 수엽 (樹葉)과 야초 류를 즐겨 채식하는 습성이 강하기 때문에 이 를 잘 적용하면 어느 정도 사료비를 낮출 수 있을 것으로 판단된다.

국내에서 사육되고 있는 sika deer, red deer 및 elk의 채식습성을 Hofmann (1985)에 의하면 수엽(樹葉)을 강하게 선택채식 (concentrate selectors) 하는 흰꼬리사슴과 사초류를 주로 채식(Grazer) 하는 소와의 중간 형 (intermediate)으로 분류하 고 있다. 한편 이 등 (1990)은 꽃사슴의 경우 수엽류, 광엽초류 및 화본과 초류중 수엽류를 61.3\% 채식하였다고 하였으며, Currie 등 (1977), Willms 등 (1980) 및 Bryant 등 (1979)도 사슴의 경우 특히 수엽류를 더 즐겨 채식하는 습성이 강하다고 보고한 바 있다.

따라서 본 연구는 사슴의 채식습성을 밝혀 조사료위주의 사양관리체계를 확립하기 위한 기초자료로 활용하고자 수행하였다.

\section{II. 재료 및 방법}

본 연구는 2007년 3월부터 12월까지 수행하 였으며, 공시시료는 화본과목초(grasses)는 Lolium perenne, Festuca arundinacea, Poa pratensis, Agrostis alba 및 mixed grass의 5종, 두과목초 (legumes)는 Trifolium pratense, Medicago sativa, Trifolium repens, Melilotus officinalis 및 Vicia villosa의 5종, 수엽(樹葉, browse)은 Quercus serrata Thunb., Prunus jamasakura Sieb., Quercus aliena Blume, Robinia pseudoaccacia 및 Pinus densiflora의 5종과 잡초 (weeds)는 Artemisia princeps Pampanini, Erigeron canadensis, Alopecurus aegualis Sobolewski, Echinochloa crusgalli var. frumentacea (Roxb.) Wight 및 Rumex crispus의 5종, 야초(Weeds)는 Zoysia japonica Steudel, Agropyron tsukushiense var. transiens (HACK) Ohwi., Arundinella hirta (Thunb.) Tanaka, Miscanthus sinensis Anderss 및 Phragmites comunis Trin의 5종 등 총 25종 을 공시하였다.

수확시기는 화본과와 두과 목초는 2번초(초 고 $30 \mathrm{~cm}$ 내외)를 기준으로 6 월 4 일에 각각 예 취하였고, 수엽은 5월 31일 수확하였는데 잎이 무성한 시기로 새잎이 함께 돋는 시기였다. 잡 초는 경작지에서 5월 28일 예취 하였는데 수확 시기는 출수 또는 개화전이였고, 야초는 비경 작지인 야산에서 5월 29일 예취하였으며 수확 시기는 출수전이였다. 수확한 시료는 시멘트 포장 운동장에서 5 6일간 양건시킨 후 $2 \mathrm{~cm}$ 내외로 세절한 뒤 비닐주머니에 담아 냉장 보 관하였다.

급여할 시료는 양건한 재료를 건물기준으로 시료 당 $500 \mathrm{~g}$ 씩을 비닐주머니에 담아 준비하 였다. 분석용 시료는 동일한 방법으로 얻어진 시료를 분쇄하여 분석하였다. 시험축은 꽃사슴 (싱 5 두를 공시하였으며, 평균체중은 $92.5 \mathrm{~kg}$ 이 었다.

시료는 초종 당 건물기준으로 $500 \mathrm{~g}$ 씩 25종 으로 총 $12.5 \mathrm{~kg}$ 을 급여하였다. 시험시간은 2007년 8월 2일 전북 남원시 운봉읍소재 가축 유전자원시험장 축사내에서 오전 8시부터 8월 3 일 오전 6시까지 실시하였으며, 물은 자유 채 
식시켰고, 시료는 움직이지 못하도록 $20 \mathrm{~kg}$ 용 량의 4각 고무물통에 담아 뷔페식으로 수행하 였다. 25종의 시료는 시료의 특성을 고려하고 골라먹는 것을 방지하기 위하여 수엽류 $\rightarrow$ 화본 과목초류 $\rightarrow$ 야초류 $\rightarrow$ 두과목초류 $\rightarrow$ 잡초류의 순으 로 1 초종씩 교대로 시계방향으로 1 번에서 25 번 까지 배치하였다. 채식량은 시료별로 8월 2일 10시, 12시, 14시, 16시, 18시 및 익일 06시에 총 6 회에 걸처 조사하여 각각 잔량을 조사한 뒤 급여량에서 잔량으로 빼서 채식량을 산출하 였고, 이를 근거로 시료별 총 채식량을 산출하 였다. Crude protein (CP)은 AOAC (1990) 방법 으로, neutral detergent fiber (NDF), acid detergent fiber (ADF) 및 lignin은 Goering과 Van Soest (1970) 방법으로, cellulose는 Crampton과 Maynard (1938) 방법으로 분석하였다. hemicellulose는 $\mathrm{NDF}$ 와 $\mathrm{ADF}$ 의 차이로, in vitro 건 물소화율 (DMD)은 Tilly와 Terry (1963) 방법으 로 분석하였다. 통계처리는 $5 \%$ 수준 범위 내에 서 유의성을 검정하였다(김 등, 1995).

\section{III. 결과 및 고찰}

\section{1. 화학적 성분 및 건물소화율}

조사료원별로 분석한 화학적 성분과 건물소 화율 (IVDMD)을 조사한 결과는 Table 1에서 보는 바와 같다. 조단백질 $(\mathrm{CP})$ 함량은 대체적 으로 화본과목초류와 두과목초류에서 높았던 반면에 수엽류와 잡초류는 중간이었으며 야초 류는 낮은 결과를 보여 채취장소, 초종, 생육단 계 및 예취시기에 따라 $\mathrm{CP}$ 함량이 차이를 보 이고 있음이 확인되었다. 이러한 양상은 조사 료원 (화본과목초류, 두과목초류, 수엽류, 잡초 류 및 야초류)내의 각 5종의 조사료 간에도 채 취장소, 초종, 생육단계 및 예취시기에 따른 $\mathrm{CP}$ 함량의 차이를 확인할 수 있었다 $(\mathrm{p}<0.05)$.

NDF (neutral detergent fiber), ADF (acid detergent fiber), hemicellulose, cellulose, lignin
함량 및 IVDMD도 역시 $\mathrm{CP}$ 함량의 변화와 마 찬가지로 채취장소, 초종, 생육단계 및 예취시 기에 따라 조사료원별로 차이를 보였으며, 역 시 각각의 조사료원내 5종간에서도 이들 함량 의 차이를 확인할 수 있었다 $(\mathrm{p}<0.05)$.

이러한 결과는 Ulyatt (1981), Frame과 Harkess (1987), 이 등(1987) 및 Osoro와 Cebrian(1989) 등의 연구결과에서도 초종에 따라 화학적 성분 이 달라질 수 있음이 밝혀졌고, Givens 등 (1993)은 계절변화에 따라서, 이와 이(1995)는 초지의 유형에 따라서도 화학적 성분이 달라질 수 있음을 보고한 바 있다. 한편, 이 등(1990) 의 연구결과에서도 수엽류의 화학적 성분과 건 물소화율이 수엽의 종류와 계절 및 수확시기에 따라 상당한 차이가 있음이 밝혀졌고, Wood와 Tanner(1985)도 시료의 채취장소와 주변 환경조 건 및 채취시기에 따라서 화학적 성분과 건물 소화율이 달라질 수 있음을 보고하고 있어 본 시험결과를 뒷받침하고 있다고 하겠다.

\section{2. 채식량, 채식비율 및 채식순위}

꽃사슴의 채식량, 채식비율 및 채식순위를 조사한 결과는 Table 2와 같다. 채식량이 가장 많았던 조사료는 Quercus aliena Blume(갈참나 무 잎)으로 급여 후 12 시전에 $500 \mathrm{~g}$ 을 완전히 채식하여 채식비율과 채식순위가 가장 높았으 며, 다음이 Prunus jamasakura Sieb.(벚나무 잎) 으로 14시전에 $491 \mathrm{~g}$ 을 채식하였고, Quercus serrata Thunb.(졸참나무 잎)도 18시전에 491g을 채식하였으나, Prunus jamasakura Sieb.를 더 빠 른 시간에 채식하였다. 다음은 Trifolium pratense (red clover)로 481g을 채식하였고, Medicago sativa (alfalfa)는 $477 \mathrm{~g}$ 을 채식하였다. 그러나 Phragmites comunis Trin(갈대, 8g)와 Zoysia japonica Steudel (잔디, 18g), Echinochloa crusgalli var. frumentacea (Roxb.) Wight (피, 22g), Agropyron tsukushiense var. transiens (HACK) Ohwi.(개밀, 24g), Miscanthus sinensis Anderss (억새, 28g), 
Table 1. Chemical composition and in vitro dry matter digestibility (IVDMD) of roughage sources (DM, \%) fed to sika deer (Servus nippon)

\begin{tabular}{|c|c|c|c|c|c|c|c|}
\hline Roughage sources & $\mathrm{CP}$ & NDF & $\mathrm{ADF}$ & $\begin{array}{l}\text { Hemi- } \\
\text { celluse }\end{array}$ & Cellulose & Lignin & IVDMD \\
\hline \multicolumn{8}{|l|}{ Grasses } \\
\hline Lolium perenne & $18.7^{\mathrm{b}}$ & $57.7^{\mathrm{e}}$ & $27.6^{\mathrm{e}}$ & $30.1^{\mathrm{c}}$ & $23.1^{\mathrm{c}}$ & $4.0^{\mathrm{d}}$ & $70.4^{\mathrm{b}}$ \\
\hline Festuca arundinacea & $18.3^{\mathrm{bc}}$ & $59.6^{\mathrm{c}}$ & $30.9^{\mathrm{b}}$ & $28.6^{\mathrm{d}}$ & $24.3^{\mathrm{a}}$ & $5.7^{\mathrm{b}}$ & $69.8^{c}$ \\
\hline Poa pratensis & $20.7^{\mathrm{a}}$ & $58.2^{\mathrm{d}}$ & $29.9^{c}$ & $28.3^{\mathrm{e}}$ & $23.8^{\mathrm{b}}$ & $6.2^{\mathrm{a}}$ & $70.5^{\mathrm{b}}$ \\
\hline Agrostis alba & $18.0^{\mathrm{C}}$ & $68.3^{\mathrm{a}}$ & $33.2^{\mathrm{a}}$ & $31.1^{\mathrm{b}}$ & $23.5^{\mathrm{bc}}$ & $5.0^{c}$ & $68.0^{\mathrm{d}}$ \\
\hline Mixed grass & $20.6^{\mathrm{a}}$ & $60.4^{\mathrm{b}}$ & $28.5^{\mathrm{d}}$ & $31.8^{\mathrm{a}}$ & $22.4^{\mathrm{d}}$ & $5.7^{\mathrm{b}}$ & $71.7^{\mathrm{a}}$ \\
\hline \multicolumn{8}{|l|}{ Legumes } \\
\hline Trifolium pratense & $15.4^{\mathrm{c}}$ & $51.9^{c}$ & $27.7^{\mathrm{d}}$ & $23.5^{\mathrm{b}}$ & $20.0^{\mathrm{d}}$ & $5.7^{\mathrm{b}}$ & $72.3^{\mathrm{a}}$ \\
\hline Medicago sativa & $16.7^{\mathrm{b}}$ & $53.2^{\mathrm{b}}$ & $26.9^{\mathrm{d}}$ & $26.3^{\mathrm{a}}$ & $21.4^{\mathrm{c}}$ & $5.1^{\mathrm{d}}$ & $72.1^{\mathrm{a}}$ \\
\hline Trifolium repens & $20.6^{\mathrm{a}}$ & $42.1^{\mathrm{e}}$ & $29.1^{\mathrm{c}}$ & $13.1^{\mathrm{d}}$ & $19.7^{\mathrm{e}}$ & $5.1^{\mathrm{d}}$ & $71.3^{\mathrm{b}}$ \\
\hline Melilotus officinalis & $16.4^{\mathrm{b}}$ & $54.3^{\mathrm{a}}$ & $34.3^{\mathrm{b}}$ & $19.9^{c}$ & $23.6^{\mathrm{b}}$ & $8.2^{\mathrm{a}}$ & $67.1^{\mathrm{c}}$ \\
\hline Vicia villosa Roth & $20.9^{\mathrm{a}}$ & $49.9^{\mathrm{d}}$ & $38.8^{\mathrm{a}}$ & $11.1^{\mathrm{e}}$ & $24.3^{\mathrm{a}}$ & $8.5^{\mathrm{a}}$ & $63.7^{\mathrm{e}}$ \\
\hline \multicolumn{8}{|l|}{ Browse } \\
\hline Quercus serrata Thunb. & $12.7^{\mathrm{c}}$ & $68.3^{\mathrm{a}}$ & $36.9^{c}$ & $31.4^{\mathrm{b}}$ & $15.9^{c}$ & $1.6^{\mathrm{C}}$ & $65.2^{\mathrm{C}}$ \\
\hline Prunus jamasakura Sieb. & $14.1^{\mathrm{b}}$ & $55.3^{\mathrm{d}}$ & $29.5^{\mathrm{d}}$ & $25.5^{\mathrm{c}}$ & $15.0^{\mathrm{e}}$ & $1.2^{\mathrm{d}}$ & $71.0^{\mathrm{b}}$ \\
\hline Quercus aliena Blume & $12.9^{c}$ & $63.9^{c}$ & $39.8^{\mathrm{b}}$ & $24.1^{\mathrm{d}}$ & $19.3^{\mathrm{b}}$ & $2.7^{\mathrm{a}}$ & $64.8^{\mathrm{c}}$ \\
\hline Robinia pseudoaccacia & $23.0^{\mathrm{a}}$ & $66.3^{\mathrm{b}}$ & $28.5^{\mathrm{e}}$ & $37.9^{\mathrm{a}}$ & $15.7^{\mathrm{d}}$ & $1.8^{\mathrm{b}}$ & $71.7^{\mathrm{a}}$ \\
\hline Pinus densiflora & $7.5^{\mathrm{d}}$ & $66.3^{\mathrm{b}}$ & $43.6^{\mathrm{a}}$ & $22.7^{\mathrm{e}}$ & $20.4^{\mathrm{a}}$ & $2.8^{\mathrm{a}}$ & $59.9^{\mathrm{d}}$ \\
\hline \multicolumn{8}{|l|}{ Weeds $^{1)}$} \\
\hline Artemisia princeps Pampanini & $12.0^{\mathrm{d}}$ & $49.6^{\mathrm{e}}$ & $32.9^{c}$ & $16.7^{\mathrm{c}}$ & $20.4^{\mathrm{c}}$ & $9.0^{\mathrm{b}}$ & $68.3^{\mathrm{b}}$ \\
\hline Erigeron canadensis & $10.2^{\mathrm{e}}$ & $50.3^{\mathrm{d}}$ & $32.7^{\mathrm{c}}$ & $17.6^{\mathrm{c}}$ & $21.5^{\mathrm{b}}$ & $9.5^{\mathrm{a}}$ & $63.5^{\mathrm{e}}$ \\
\hline Alopecurus aegualis Sobolewski & $13.6^{\mathrm{b}}$ & $68.2^{\mathrm{a}}$ & $35.6^{\mathrm{b}}$ & $32.6^{\mathrm{a}}$ & $26.5^{\mathrm{a}}$ & $7.8^{\mathrm{c}}$ & $66.2^{\mathrm{c}}$ \\
\hline $\begin{array}{l}\text { Echinochloa crusgalli var. } \\
\text { frumentacea(Roxb.) Wight }\end{array}$ & $17.5^{\mathrm{a}}$ & $64.5^{\mathrm{b}}$ & $30.4^{\mathrm{d}}$ & $34.1^{\mathrm{a}}$ & $26.2^{\mathrm{a}}$ & $6.5^{\mathrm{d}}$ & $70.2^{\mathrm{a}}$ \\
\hline Rumex crispus & $13.1^{\mathrm{c}}$ & $61.2^{\mathrm{c}}$ & $39.1^{\mathrm{a}}$ & $22.0^{\mathrm{b}}$ & $19.5^{\mathrm{d}}$ & $2.0^{\mathrm{e}}$ & $64.5^{\mathrm{d}}$ \\
\hline \multicolumn{8}{|l|}{ Native grasses $^{2}$} \\
\hline Zoysia japonica Steudel & $12.6^{\mathrm{b}}$ & $68.4^{\mathrm{d}}$ & $36.8^{\mathrm{c}}$ & $31.7^{\mathrm{a}}$ & $23.1^{\mathrm{b}}$ & $8.2^{\mathrm{d}}$ & $60.9^{\mathrm{b}}$ \\
\hline $\begin{array}{l}\text { Agropyron tsukushiense var. transiens } \\
\text { (Hack) Ohwi. }\end{array}$ & $14.0^{\mathrm{a}}$ & $67.5^{\mathrm{e}}$ & $35.9^{\mathrm{d}}$ & $31.6^{\mathrm{a}}$ & $22.5^{\mathrm{c}}$ & $7.5^{\mathrm{e}}$ & $62.9^{\mathrm{a}}$ \\
\hline Arundinella hirta(Thunb.) Tanaka & $10.0^{\mathrm{c}}$ & $71.9^{c}$ & $42.4^{\mathrm{b}}$ & $29.5^{\mathrm{b}}$ & $32.3^{\mathrm{a}}$ & $11.5^{\mathrm{b}}$ & $58.5^{\mathrm{c}}$ \\
\hline Miscanthus sinensis Anderss & $7.4^{\mathrm{d}}$ & $73.7^{\mathrm{b}}$ & $42.7^{\mathrm{b}}$ & $30.9^{\mathrm{ab}}$ & $32.8^{\mathrm{a}}$ & $10.0^{\mathrm{c}}$ & $57.6^{\mathrm{d}}$ \\
\hline Phragmites comunis Trin & $9.9^{c}$ & $74.7^{\mathrm{a}}$ & $44.9^{\mathrm{a}}$ & $29.8^{\mathrm{b}}$ & $32.4^{\mathrm{a}}$ & $12.9^{\mathrm{a}}$ & $55.9^{\mathrm{e}}$ \\
\hline
\end{tabular}

CP; Crude protein, NDF; Neutral detergent fiber, ADF; Acid detergent fiber, IVDMD; In vitro dry matter digestibility.

a, b, c Means in the same column with different letters were significantly different $(\mathrm{p}<0.05)$

1) Harvested in cultivated field.

2) Harvested in uncultivated field.

Arundinella hirta (Thunb.) Tanaka (새, 31g) 및 Alopecurus aegualis Sobolewski (뚝새풀, 42g) 등 은 채식량이 $50 \mathrm{~g}$ 미만으로 채식비율과 순위가
상당히 낮은 결과를 보였다.

대체적으로 채식량이 높은 조사료는 Table 1 에서와 같이 $\mathrm{NDF}, \mathrm{ADF}$ 와 같은 섬유소물질의 
Table 2. Dry matter intake, relative intake percentage and intake ranking of sika deer (Servus nippon) fed with various roughage sources

\begin{tabular}{|c|c|c|c|c|c|c|c|c|c|c|}
\hline \multirow[b]{2}{*}{ Roughage sources } & \multirow{2}{*}{$\begin{array}{c}\text { DM } \\
\text { offered } \\
\text { (g) }\end{array}$} & \multicolumn{6}{|c|}{ DM intake (g) } & \multirow{2}{*}{$\begin{array}{l}\text { Total } \\
\text { intake } \\
\text { (g) }\end{array}$} & \multirow{2}{*}{$\begin{array}{c}\text { RI } \\
(\%)^{*}\end{array}$} & \multirow{2}{*}{$\begin{array}{c}\text { Intake } \\
\text { rank- } \\
\text { ing }\end{array}$} \\
\hline & & $\begin{array}{l}08: 00- \\
10: 00\end{array}$ & $\begin{array}{l}10: 00- \\
12: 00\end{array}$ & $\begin{array}{l}12: 00- \\
14: 00\end{array}$ & $\begin{array}{l}14: 00- \\
16: 00\end{array}$ & $\begin{array}{l}16: 00- \\
18: 00\end{array}$ & $\begin{array}{l}\text { 18:00- } \\
06: 00\end{array}$ & & & \\
\hline \multicolumn{11}{|l|}{ Grasses } \\
\hline Lolium perenne & 500 & 24 & 42 & 36 & 24 & 26 & 24 & 176 & 2.86 & 14 \\
\hline Festuca arundinacea Schr. & 500 & 12 & 24 & 21 & 16 & 9 & 5 & 87 & 1.42 & 17 \\
\hline Poa pratensis & 500 & 8 & 36 & 38 & 16 & 0 & 0 & 98 & 1.60 & 16 \\
\hline Agrostis alba & 500 & 11 & 18 & 24 & 11 & 0 & 0 & 64 & 1.04 & 18 \\
\hline Mixed grass & 500 & 28 & 271 & 87 & 24 & 19 & 9 & 438 & 7.13 & 9 \\
\hline \multicolumn{11}{|l|}{ Legumes } \\
\hline Trifolium pratense & 500 & 120 & 154 & 112 & 48 & 37 & 10 & 481 & 7.83 & 4 \\
\hline Medicago sativa & 500 & 24 & 136 & 154 & 109 & 49 & 5 & 477 & 7.76 & 5 \\
\hline Trifolium repens & 500 & 209 & 124 & 87 & 28 & 7 & 0 & 455 & 7.40 & 7 \\
\hline Melilotus officinalis & 500 & 30 & 56 & 64 & 56 & 30 & 9 & 245 & 3.99 & 12 \\
\hline Vicia villosa Roth & 500 & 197 & 174 & 46 & 23 & 4 & 0 & 444 & 7.22 & 8 \\
\hline \multicolumn{11}{|l|}{ Browse } \\
\hline Quercus serrata Thunb. & 500 & 224 & 117 & 69 & 66 & 15 & 0 & 491 & 7.99 & 3 \\
\hline Prunus jamasakura Sieb. & 500 & 396 & 87 & 8 & 0 & 0 & 0 & 491 & 7.99 & 2 \\
\hline Quercus aliena Blume & 500 & 474 & 26 & 0 & 0 & 0 & 0 & 500 & 8.14 & 1 \\
\hline Robinia pseudoaccacia & 500 & 305 & 81 & 64 & 17 & 10 & 0 & 477 & 7.76 & 6 \\
\hline Pinus densiflora & 500 & 56 & 37 & 42 & 64 & 57 & 30 & 286 & 4.65 & 11 \\
\hline \multicolumn{11}{|l|}{ Weeds } \\
\hline Artemisia princeps Pampanini & 500 & 36 & 28 & 18 & 21 & 5 & 0 & 108 & 1.76 & 15 \\
\hline Erigeron canadensis & 500 & 32 & 38 & 30 & 246 & 79 & 12 & 437 & 7.11 & 10 \\
\hline Alopecurus aegualis Sobolewski & 500 & 0 & 0 & 12 & 13 & 17 & 0 & 42 & 0.68 & 19 \\
\hline $\begin{array}{l}\text { Echinochloa crusgalli var. } \\
\text { frumentacea(Roxb.) Wight }\end{array}$ & 500 & 0 & 0 & 0 & 12 & 10 & 0 & 22 & 0.36 & 23 \\
\hline Rumex crispus & 500 & 18 & 51 & 49 & 46 & 42 & 12 & 218 & 3.55 & 13 \\
\hline \multicolumn{11}{|l|}{ Native grasses } \\
\hline Zoysia japonica Steudel & 500 & 0 & 0 & 0 & 9 & 9 & 0 & 18 & 0.29 & 24 \\
\hline $\begin{array}{l}\text { Agropyron tsukushiense var. } \\
\text { transiens (Hack) Ohwi. }\end{array}$ & 500 & 0 & 0 & 14 & 6 & 4 & 0 & 24 & 0.39 & 22 \\
\hline Arundinella hirta(Thunb.) Tanaka & 500 & 0 & 0 & 11 & 8 & 12 & 0 & 31 & 0.50 & 20 \\
\hline Miscanthus sinensis Anderss & 500 & 0 & 0 & 0 & 18 & 10 & 0 & 28 & 0.46 & 21 \\
\hline Phragmites comunis Trin & 500 & 0 & 0 & 0 & 0 & 8 & 0 & 8 & 0.13 & 25 \\
\hline
\end{tabular}

* RI(\%) ; Relative intake percentage $\{$ each species intake(g)/total intake(g)×100)\}. 
함량이 낮은 반면에 IVDMD가 높은 편이였으 나, 채식량이 낮은 조사료는 $\mathrm{NDF}, \mathrm{ADF}$ 와 같은 섬유소물질의 함량이 높았던 반면에 IVDMD는 상대적으로 낮은 결과를 나타내어 Holecheck와 Vavra (1982) 및 Kirby와 Stuth(1982)의 연구결 과와 상당히 부합되는 결과를 얻었다. 이에 대 해서는 Dulpy(1979)도 NDF 함량과 채식량간에 부의 상관관계가 있음을 지적한 바 있다.

그러나 Quercus aliena Blume, Quercus serrata Thunb. 및 Prunus jamasakura Sieb. 등은 화본 과목초나 두과목초에 비하여 상대적으로 섬유 소물질의 함량이 높고, IVDMD도 낮은 데에도 불구하고 채식량이 상당히 높게 나온 것은 사 슴이 유산양 (이와 이, 2007)이나 재래산양 (이 등, 1995)에 비하여 수엽류에 대한 선택 채식습 성이 강하게 나타났기 때문이라 하겠다. 이 등 (1990)도 꽃사슴은 광엽초류 (29.7\%), 화본과초 류(9.0\%)에 비해 수엽류를 $61.3 \%$ 채식하였다고 보고한 바 있으며, Currie (1977), Willms 등 (1980) 및 Bryant 등 (1979)도 사슴이 수엽류를 즐겨 채식하는 습성이 강하다고 보고하고 있 다. Hofmann (1985)에 의하면 흰꼬리사슴(concentrate selectors)과 같이 야생에 가까울수록 수엽 을 더 강하게 선택채식하고, 가축화된 sika deer, red deer 및 elk 등은 중간정도(intermediate) 의 선택채식 습성을 보이지만 소나 면양에 비 하여서는 수엽을 더 즐겨 채식하는 습성이 강 하다고 하였다.

본 시험결과에서는 대체적으로 몇 가지 조사 료 원을 제외하고는 상대적으로 $\mathrm{NDF}$ 나 $\mathrm{ADF}$ 와 같은 섬유소물질의 함량이 낮고 건물소화율이 높았던 조사료에서 채식량이 높은 양상을 보이 고 있는 데, Greenhal과 Wainmann (1979)은 사 초의 품질이 채식량에 영향을 주는 주요인이라 고 하였고, Jarrige 등(1974)과 Hodgson 등 (1977)은 채식량과 건물소화율 간에 정의 상관 관계가 있음을 보고한 바 있어 품질이 채식량 의 증감에 미치는 영향이 크기 때문이라 하겠 다. 그러나 가축의 채식량에 영향을 주는 요인
은 매우 다양하게 보고되고 있는데 Arthun (1981)은 가축이 화본과 보다는 두과초류를 더 즐겨 채식한다고 하였고, Peel과 Green (1984)은 초종구성이 채식량에 영향을 주는 요인이라 보 고한 바 있다. 또한 Henry (1978)는 계절에 따 라 초종에 따른 채식기호성이 달라 채식량이 달랐음을 지적한 바 있으며, Givens 등 (1993)은 사초의 숙기가 채식량에 영향을 주는 요인이라 밝히고 있어 채식량의 증감에 미치는 요인이 다양함을 시사하고 있다고 하겠다.

\section{3. 조사료원별 채식량 및 채식비율}

조사료원별 각각 5 종간의 섭취량과 채식비율 을 조사한 결과는 Table 3에서 보는 바와 같다. 조사료원별 각각 5 종간의 채식량과 채식비율은 초종이나 수종 간에 차이를 보였다. 즉, 화본과 목초내의 5종중에서 혼합목초 (Mixed grass)의 채식량과 채식비율이 가장 높았던 반면에 Agrostis alba (redtop)가 가장 낮은 결과를 나타 내었다.

두과목초 5종중에서는 Trifolium pratense (red clover)가 가장 높았던 반면에 Melilotus officinalis (sweet clover)가 가장 낮았으며, 수엽 5종중에 서는 Quercus aliena Blume(갈참나무)가 높았 고 Pinus densiflora (소나무)가 가장 낮았으며, 잡초 5종중에서는 Erigeron canadensis(망초)가 높았던 반면에 Echinochloa crusgalli var. frumentacea (Roxb.) Wight(피)가 가장 낮았으며, 야초 5종중에서는 Arundinella hirta (Thunb.) Tanaka(새)가 높은 반면에 Phragmites comunis Trin (갈대)가 가장 낮은 결과를 보였다.

이러한 결과는 Table 1 에서 언급한 바와 같 이 채취장소, 초종, 생육단계 및 예취시기에 따 른 화학적 성분과 건물소화율의 차이 때문에 얻어진 결과 일 뿐 아니라 (Ulyatt, 1981; Wood 와 Tanner, 1985; Frame과 Harkess, 1987; 이 등, 1987; Osoro와 Cebrian, 1989), 사슴의 고유 한 채식습성 (Arnold 등, 1979; 이 등, 1990) 때 
Table 3. Dry matter intake and percentage of sika deer(Servus nippon) fed with various roughage sources

\begin{tabular}{|c|c|c|}
\hline \multirow{2}{*}{ Roughage sources } & \multicolumn{2}{|c|}{ Dry matter Intake } \\
\hline & (g) & (\%) \\
\hline \multicolumn{3}{|l|}{ Grasses } \\
\hline Mixed grass & 438 & 50.8 \\
\hline Lolium perenne & 176 & 20.4 \\
\hline Poa pratensis & 98 & 11.3 \\
\hline Festuca arundinacea Schr. & 87 & 10.1 \\
\hline Agrostis alba & 64 & 7.4 \\
\hline Sub total & 863 & 100 \\
\hline \multicolumn{3}{|l|}{ Legumes } \\
\hline Trifolium pratense & 481 & 22.9 \\
\hline Medicago sativa & 477 & 22.7 \\
\hline Trifolium repens & 455 & 21.6 \\
\hline Vicia villosa Roth & 444 & 21.1 \\
\hline Melilotus officinalis & 245 & 11.7 \\
\hline Sub total & 2,102 & 100 \\
\hline \multicolumn{3}{|l|}{ Browse } \\
\hline Quercus aliena Blume & 500 & 22.3 \\
\hline Quercus serrata Thunb. & 491 & 21.9 \\
\hline Prunus jamasakura Sieb. & 491 & 21.9 \\
\hline Robinia pseudoaccacia & 477 & 21.2 \\
\hline Pinus densiflora & 286 & 12.7 \\
\hline Sub total & 2,245 & 100 \\
\hline \multicolumn{3}{|l|}{ Weeds } \\
\hline Erigeron canadensis & 437 & 52.8 \\
\hline Rumex crispus & 218 & 26.4 \\
\hline Artemisia princeps Pampanini & 108 & 13.0 \\
\hline Alopecurus aegualis Sobolewski & 42 & 5.1 \\
\hline Echinochloa crusgalli var. frumentacea (Roxb.) Wight & 22 & 2.7 \\
\hline Sub total & 827 & 100 \\
\hline \multicolumn{3}{|l|}{ Native grasses } \\
\hline Arundinella hirta (Thunb.) Tanaka & 31 & 28.4 \\
\hline Miscanthus sinensis Anderss. & 28 & 25.7 \\
\hline Agropyron tsukushiense var. transiens (HACK) Ohwi. & 24 & 22.0 \\
\hline Zoysia japonica Steudel & 18 & 16.5 \\
\hline Phragmites comunis Trin & 8 & 7.4 \\
\hline Sub total & 109 & 100 \\
\hline
\end{tabular}

문이라 하겠다. 이러한 양상은 이와 이 (2007) 가 유 산양으로 시험하였던 결과와 차이를 보 이고 있어 채식습성이 축종에 따라 차이를 보 이고 있음을 확인할 수 있었다.

\section{4. 채식습성}

채식량, 채식비율 및 채식순위를 근거로 한 꽃사슴의 채식습성은 Table 4에서 보는 바와 
Table 4. Food habits of sika deer (Servus nippon)

\begin{tabular}{lccc}
\hline \multirow{2}{*}{ Roughage sources } & \multicolumn{2}{c}{ Dry matter intake } & \multirow{2}{*}{ Intake order } \\
\cline { 2 - 3 } & $(\mathrm{g})$ & 36.5 & 1 \\
\hline Browse & 2,245 & 34.2 & 2 \\
Legumes & 2,102 & 14.0 & 3 \\
Grasses & 863 & 13.5 & 4 \\
Weeds & 827 & 1.8 & 5 \\
Native grasses & 109 & 100 & 6 \\
Total & 6,146 & & \\
\hline
\end{tabular}

같다. 꽃사슴은 수엽을 $36.5 \%$ 채식하였고, 두과 목초를 $34.2 \%$ 채식하였던 반면에 화본과목초는 $14.0 \%$, 야초는 $13.5 \%$ 및 잡초는 $1.8 \%$ 를 채식 하였다. 이러한 결과는 Hofmann(1985)이나 Currie 등 (1977), Willms 등 (1980), Korschgen 등(1980) 및 이 등 (1990)이 밝힌 바와 같이 꽃 사슴은 유 산양 (이와 이, 2007)에 비하여 수엽 을 더 강하게 선택채식 하는 습성이 강하게 나 타났기 때문이라 하겠다. 또한 Bryant 등 (1979) 에 의하면 사슴이 산양이나 면양에 비하여 상 대적으로 수엽류의 채식비율이 가장 높게 나타 났음이 밝혀졌는데, Henry (1978)도 노루의 경 우 수엽류의 채식비율이 광엽초류나 화본과 초 류에 비하여 년중 높게 나타났다고 보고하고 있어 야생동물에 가까울수록 수엽류를 선택채 식하는 습성이 강하게 나타남을 암시하고 있다 고 하겠다.

$$
\text { IV. 요 약 }
$$

본 연구는 2007년 3월부터 12월까지 충남대 학교 부속사육장 및 전북 남원시 운봉읍 소재 가축유전자원시험장에서 수행하였다. 공시시료 는 화본과목초(grasses)는 Lolium perenne, Festuca arundinacea, Poa pratensis, Agrostis alba 및 mixed grass의 5종과, 두과목초 (legumes)는 Trifolium pratense, Medicago sativa,
Trifolium repens, Melilotus officinalis 및 Vicia villosa의 5종, 수엽 (browse)으로 Quercus serrata Thunb., Prunus jamasakura Sieb., Quercus aliena Blume, Robinia pseudoaccacia 및 Pinus densiflora의 5종과 잡초 (weeds)는 Artemisia princeps Pampanini, Erigeron canadensis, Alopecurus aegualis Sobolewski, Echinochloa crusgalli var. frumentacea (Roxb.) Wight 및 Rumex crispus의 5종을, 야초(Weeds)는 Zoysia japonica Steudel, Agropyron tsukushiense var. transiens (HACK) Ohwi., Arundinella hirta (Thunb.) Tanaka, Miscanthus sinensis Anderss 및 Phragmites comunis Trin의 5종 등 총 25종 을 공시하였다. 시험축은 꽃사슴(1) 5 두를 공 시하였으며, 평균체중은 $92.5 \mathrm{~kg}$ 이었다. 시료는 초종 당 건물기준으로 $0.5 \mathrm{~kg}$ 씩 급여하여 시험 하였으로 시험결과는 다음과 같다. 공시시료의 조사료원별로 분석한 화학적 성분과 건물소화 율은 대체적으로 채취장소, 초종, 생육단계 및 예취시기에 따라 차이를 보였다. 채식량, 채식 비율 및 채식순위는 초종 및 수종에 따라 차이 를 보였으며, 대체적으로 섬유소물질의 함량이 낮은 반면에 건물소화율이 높은 조사료를 더 즐겨 채식하는 양상을 나타내었다. 꽃사슴은 Quercus aliena Blume (갈참나무 잎, 500g)을 가 장 즐겨 채식하였으며, 다음은 Prunus jamasakura Sieb. (벚나무 잎, 491g)과 Quercus 
serrata Thunb. (졸참나무 잎, 491g), Trifolium pratense (red clover, 481g) 순으로 즐겨 채식하 였던 반면에, Phragmites comunis Trin(갈대, $8 \mathrm{~g})$ 를 가장 적게 채식하였다. 꽃사슴의 채식습 성은 수엽 $36.5 \%$, 두과목초 $34.2 \%$, 화본과목초 $14.0 \%$, 야초는 $13.5 \%$ 및 잡초를 $1.8 \%$ 채식하 였던 것으로 보아 채식습성은 전형적인 수엽채 식형 (browser type)에 가깝다고 하겠다.

\section{$\mathrm{V}$. 인 용 문 헌}

1. 김내수, 김정우, 박홍양, 상병찬, 여정수, 전광주, 최광수, 홍기창. 1995. 응용통계학. 유한문화사. 서울.

2. 이인덕, 명 전, 송석우, 전영기. 1987. 초종구성 비율이 산양의 섭취량, 소화율 및 선택채식성에 미치는 영향. 한초지. 7(1):31-36.

3. 이인덕, 이중해, 이형석. 1995. Alfalfa를 첨가한 갈참수엽 급여 산양의 섭취량, 소화율과 질소 및 에너지 이용에 관한 연구. 한초지. 15(4):291-296.

4. 이인덕, 이형석. 2007. 여러 가지 조사료를 급여 한 유산양(Saanen)의 채식습성에 관한 연구. 한 초지. 27(4):313-322.

5. 이중해, 이인덕, 이형석. 1990. 꽃사슴의 수엽류 이용에 관한 연구. 2. 수엽류의 화학적 성분, 생 산량 및 섭취량. 한축지. 32(2):109-118.

6. 이형석, 이인덕. 1995. 산양에 의한 초지유형별 목초의 섭취량 및 영양가치 이용성 비교. 한초 지. 15(4):297-302.

7. AOAC. 1990. Official methods of analysis (15th ed.) Association of Official Analytical Chemists. Washington, DC.

8. Arnold, G.W. 1979. The special senses in grazing animals. I. Sight and dietary habit in sheep. Aust. J. Agr. Res. 17:521-529.

9. Arthun, d. 1981. Size number and chemical composition of defecation from steer fed four different roughage diets. M.S. Thesis, New Mexico State Univ. Las Cruces. 103.

10. Bryant, F.C., M.M. Kothmann and L.B. Merrill. 1979. Diets of sheep, Angora goats, Spanish goats and white-tailed deer under excellent range conditions. J. Range Manage. 32:412-417.
11. Crampton, F. W. and L. A. Maynard. 1938. The relation of cellulose and lignin content to the nutritive value of animal feeds. J. Nut. 15:383395.

12. Currie, P.O., D.W. Reicher, J.C. Malechek and O. C. Wallmo. 1977. Forage selcetion comparisons for mule deer and cattle under manage ponderosa pine. J. Range Manage. 30:352-356.

13. Dulphy, J.P. 1979. The intake of conserved forage. Forage conservation in the 80'S. Occasional Symposium No. 11. British Grassl. Soci. pp. 107-121.

14. Frame, J. and R.D. Harkess. 1987. The productivity of farm forage legumes sown alone and with each of five companion grasses. Grass and Forage Sci. 42:213-223.

15. Givens, D.I., A.R. Moss and A.H. Adamson. 1993. Influence of growth stage and season on the energy value of fresh herbage. I . Changes in metabolizable energy content. Grass and Forage Sci. 48:166-174.

16. Goring, H.K. and P.J. Van Soest. 1970. Forage fiber analysis. Agr. Handbook. No. 379. ARS. USDA. Washington, DC.

17. Henry, B.A.M. 1978. Diet of roe deer in English conifer forest. J. Wildl. Manage. 42:937-940.

18. Greenhalgh, J.F.D. and F.W. Wainman. 1979. The utilization of energy in conserved forage. Forage conservation in the 80's Occasional Symposium. No. 11. Brit. Grassland Sci. pp. 121-129.

19. Hodgson, J., J.M. Rodrigeuz Capriles and J.S. Fenlon. 1977. The influence of herbage characteristics on the herbage intake of grazing calves. J. Agri. Sci. Cambridge. 89:743-750.

20. Hofmann, R.R. 1985. Digestive physiology of the deer-their morphphysiological specialization and adaptation. In; Biology of deer production. Eds. Fennessy, P. F., and Drew. F. R. Royal Society of New Zealand. pp. 393-407.

21. Holecheck, J.L. and M. Vavra. 1982. Forage intake by cattle on forest and grassland ranges. J. Range Manage. 35(6):737-740.

22. Jarrige, R., G. Demarquilly, and J.P. Dulphy. 1974. The voluntary intake of forage. Proceedings of the fifth general meeting European Grassland Federation. Upsala. Plant husbandry. 28:98-106. 
23. Kirby, D.R. and J.W. Stuth. 1982. Seasonal Diurnal variation in composition of cow diets. J. Range Manage. 35(1):7-8.

24. Korschgen, L.J., W.R. Porath and O. Torgerson. 1980. Spring and summer foods of deer in the Missouri Ozarks. J. Wild. Manage. 44:89-97.

25. Osoro, K. and M. Cebrian. 1989. Digestibility of energy and gross energy intake in fresh pasture. Grass and forage Sci. 44:41-46.

26. Peel, S. and Green, J.O. 1984. Sward composition and output on grassland farms. Grass and Forage Sci. 39:107-110.

27. Tilley, J.A.M. and R.A. Terry. 1963. A two stage technique for in vitro digestibility of forage crops. J. Brit. Grassl. Sci. 18:104-111.

28. Ulyatt, M.J. 1981. The feeding value of temperate pasture factors affecting forage intake by range ruminants. J. Range Manage. 38:305-312.

29. Willms, W., A. McLean, R. Tucker and R. Ritcey. 1980. Deer and cattle diets on summer range in British Columbia. J. Range Manage. 33(1):55-59.

30. Wood, J.M. and G.W. Tanner. 1985. Browse quality response to forest fertilization and soils in Florida. J. Range Manage. 38(5):432-435.

(접수일자 : 2008. 2. 22 / 채택일자 : 2008. 3. 5) 